Review

\title{
Q1 The role of microRNAs in the pathogenesis of autoimmune diseases
}

\author{
Q2 Ji-Qing Chen ${ }^{\mathrm{a}}$, Gábor Papp ${ }^{\mathrm{a}}$, Péter Szodoray ${ }^{\mathrm{b}}$, Margit Zeher ${ }^{\mathrm{a}, *}$
}

a Division of Clinical Immunology, Faculty of Medicine, University of Debrecen, Móricz Zs. str. 22, H-4032 Debrecen, Hungary
b Centre for Immune Regulation, Department of Immunology, University of Oslo, Oslo University Hospital, Rikshospitalet, Oslo, Norway

\section{A R T I C L E I N F O}

\section{Article history:}

Received 6 July 2016

Accepted 10 July 2016

Available online xxxx

\section{Keywords:}

MicroRNAs (miRs)

Systemic lupus erythematosus (SLE)

Primary Sjögren's syndrome (SS)

Rheumatoid arthritis (RA)

Systemic sclerosis (SSc)

Multiple sclerosis (MS)

Psoriasis

\begin{abstract}
A B S T R A C T
MicroRNAs (miRNAs) are single-stranded, endogenous non-coding small RNAs, ranging from 18 to 25 nucleo- 17 tides in length. Growing evidence suggests that miRNAs are essential in regulating gene expression, cell develop- 18 ment, differentiation and function. Autoimmune diseases are a family of chronic systemic inflammatory diseases. 19 Recent findings on miRNA expression profiles have been suggesting their role as biomarkers in autoimmune 20 diseases such as systemic lupus erythematosus, rheumatoid arthritis and Sjögren's syndrome. In this review, 21 we summarize the characteristics of miRNAs and their functional role in the immune system and autoimmune 22 diseases including systemic lupus erythematosus, primary Sjögren's syndrome, rheumatoid arthritis, systemic 23 sclerosis, multiple sclerosis and psoriasis; moreover, we depict the advantages of miRNAs in modern diagnostics. 24
\end{abstract} (C) 2016 Published by Elsevier B.V. 25

\section{Contents}

1. Introduction . . . . . . . . . . . . . . . . . . . . . . . . . . . . . . . . . . . . . . . . 0

2. The biology of miRNAs ... . . . . . . . . . . . . . . . . . . . . . . . . . . . . . . 0

3. miRNAs in immune system . . . . . . . . . . . . . . . . . . . . . . . . . . . . . . . . . . . . . . . . . . . 0

3.1. Innate immunity . . . . . . . . . . . . . . . . . . . . . . . . . . . . . . . . . . . 0

3.2. Adaptive immunity . . . . . . . . . . . . . . . . . . . . . . . . . . . . . . . . . . . . . . . . . 0

4. MiRNAs in autoimmune diseases . . . . . . . . . . . . . . . . . . . . . . . . . . . . . . . . . . . . . . . . . . . . . . . . 0

4.1. Systemic lupus erythematosus ... . . . . . . . . . . . . . . . . . . . . . . . . . . . . . . . . . . . . . . 0

4.2. Primary Sjögren's syndrome ... . . . . . . . . . . . . . . . . . . . . . . . . . . . . . . . . . . . . . . . 0

4.3. Rheumatoid arthritis . . . . . . . . . . . . . . . . . . . . . . . . . . . . . . . . . . . . 0

4.4. Systemic sclerosis . . . . . . . . . . . . . . . . . . . . . . . . . . . . . . . . . . . . . . . . 0

4.5. Multiple sclerosis .... . . . . . . . . . . . . . . . . . . . . . . . . . . . . . . . 0

4.6. Psoriasis .. . . . . . . . . . . . . . . . . . . . . . . . . . . . . . . . . . . . 0

5. Conclusions and future perspectives . . . . . . . . . . . . . . . . . . . . . . . . . . . . . . . . . . . . . . 0

Take-home messages . . . . . . . . . . . . . . . . . . . . . . . . . . . . . . . . . . . . . . . 0

Conflict of interest . . . . . . . . . . . . . . . . . . . . . . . . . . . . . . . . . 0

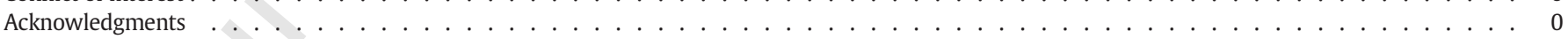

References

\section{Introduction}

MicroRNAs (miRNAs) constitute a recently discovered family of small RNAs, ranging from 18 to 25 nucleotides in length. They are

\footnotetext{
* Corresponding author.

E-mail address: zeher@iiibel.dote.hu (M. Zeher).
}

single-stranded, endogenous non-coding RNAs playing critical roles in 61 regulating gene expression $[1,2]$.

miRNAs regulate approximately $90 \%$ of protein-coding genes, and 63 play a central role in various biological processes including immune 64 call lineage commitment, differentiation, proliferation, apoptosis and 65 maintenance of immune homeostasis. It is not surprising that 66 alterations in the expression of miRNAs potentially contribute to the 67 
development of certain pathological conditions and clinical disorders. Nowadays, the pathogenetical role of miRNAs is most intensively studied in malignant diseases as well as autoimmune conditions. Changes in miRNA expression profiles have been identified in different autoimmune diseases such as systemic lupus erythematosus (SLE), rheumatoid arthritis (RA) and Sjögren's syndrome (SS) [3-5]. In this review, we summarize the characteristics of miRNAs and their functional role in the immune system and autoimmune diseases including SLE, primary SS, RA, systemic sclerosis (SSc), multiple sclerosis (MS) and psoriasis.

\section{The biology of miRNAs}

The majority of miRNA genes derived from the intergenic regions or in oriented antisense to form independent transcription units. Most of the others reside in the intron region of protein-coding genes [6]. Human miRNAs are not always genomically isolated; sometimes several miRNAs are assembled as clusters for further transcription and expression [7].

The miRNA biogenesis and maturation occur first in the nucleus and then in the cytoplasm with the help of several proteins and enzymes (Fig. 1). The first step in the miRNA biogenesis is the generation of primary miRNA transcripts (pri-miRNAs) from DNA molecules in the nucleus of the cell. Most miRNA genes are transcribed by RNA polymerase II to produce a few hundred to thousand nucleotide-long pri-miRNA [6]. The pri-miRNAs are both capped and polyadenylated with a typical hairpin structure [8]. These pri-miRNAs are recognized by an enzymeprotein complex and further cleaved into 70-100 nucleotide-long precursor miRNA (pre-miRNA). This complex is composed of Drosha and DiGeorge syndrome critical region gene 8 (DGCR8) and denoted as microprocessor complex [9]. Drosha is one of the two members of the RNase III family while DGCR8 is the double-stranded RNA-binding protein which is deleted in DiGeorge syndrome [10]. The pre-miRNA then exported to cytoplasm through exportin 5 , which is a member of the karyopherin family of nucleocytoplasmic proteins. The exportin 5 recognizes a two-nucleotide overhang left by Drosha at the $3^{\prime}$ end of the pre-miRNA hairpin, requiring the GTP-bound form of the Ran GTPase for providing energy [11].

The noncanonical miRNA biogenesis pathway bypasses the microprocessor complex cleavage processing for another sort of premiRNAs, known as mirtrons, which directly spliced out of introns by spliceosome. The branched pre-mirtrons then undergo lariatmediated debranching to mimic the structural features of pre-miRNAs $[12,13]$. Interestingly, mirtrons can not only be found in Caenorhabditis elegans and Drosophila, but also reported in mammals [14].

The pre-miRNAs have further processing to yield mature miRNA in the cytoplasm. The second member of the RNase III family named Dicer interacts with both $5^{\prime}$ and $3^{\prime}$ ends of the pre-miRNA and cleaves the hairpin loop, processing to a 19-25 nucleotides miRNA/miRNA* duplex $[15,16]$. The miRNA* was regarded as passenger strand since it is less-stable, while the miRNA as guide strand. The miRNA/miRNA* duplex releases the helix structure after loaded into the argonaute (Ago) proteins. The guide strand remains the interaction with Ago to generate the RNA-induced silencing complex (RISC), which facilitate miRNAs binds to their targets [17]. The passenger strand as complementary strand of the guide strand is degraded as a RISC complex substrate. However recent study demonstrates that several miRNA* are stably expressed and may play an important role, as well [18].

The mature miRNA interacts with the 3'-UTR of specific messenger RNA ( $m R N A$ ) to regulate gene expression. Target mRNA is recognized by the 2-7 nucleotides of the 'seed' region of the miRNA [19]. The complementary degree of the base pairing between the miRNA seed region and mRNA defines the mechanism of gene regulation [20]. When the complementary base pairing is perfect or near-perfect, Ago protein of the RISC complex induces the endonucleotic cleavage of the target mRNA resulting in deadenylation and degradation of mRNA fragments.
When the base pairing is incomplete, the formation of double-stranded 132 RNA, resulting from the binding of miRNA, leads to translational 133 repression $[2,21,22]$. Repressed mRNAs aggregate in cytoplasmic foci 134 called P-bodies, which are known sites of mRNA destabilization [23,24]. 135

\section{3. miRNAs in immune system}

The miRNAs play critical roles not only in the development of im- 137 mune system but also the regulation of both innate and adaptive immu- 138 nity [5,25]. MiRNAs function as translational repressors during stem cell 139 fate and differentiation [26]. MiR-181, miR-223 and miR-142s are 140 strongly expressed in hematopoietic cells and shown regulatory roles 141 during hematopoietic lineage differentiation $[27,28]$.

\subsection{Innate immunity}

143

The innate immune system is the first line of host defense and im- 144 portant in mechanisms against invading microorganisms; moreover, it 145 forms the basis of the development of adaptive immunity. Host cells ex- 146 press diverse pattern recognition receptors (PRRs), including toll-like 147 receptors (TLRs), C-type lectin-like receptors (CLRs), retinoic acid- 148 inducible gene (RIG)-I-like-receptors (RLRs) and nucleotide-binding 149 oligomerization domain (NOD)-like receptors (NLRs). These can recog- 150 nize a wide range of pathogen-associated molecular patterns (PAMPs). 151 These mechanisms trigger the intracellular signaling pathways, which 152 results in releasing of proinflammatory cytokines, chemokines, and in- 153 terferons (IFNs), as well as lead to the expression of co-stimulatory mol- 154 ecules [29]. TLRs are the most characterized PRRs, which are capable of 155 potently activating different cell types, which could be highly expressed 156 on most immune cells [30]. Their downstream signaling pathways lead 157 to the production of a wide range of immune-stimulatory cytokines and 158 chemokines. Aberrant activation of TLRs may result in unrestricted in- 159 flammatory responses therefore the family of TLRs may play a pivotal 160 role in the development of autoimmune diseases [31]. Among all ten 161 TLR subtypes, TLR1, TLR2, TLR4, TLR5, TLR6 and TLR10 are generally 162 regarded as extracellular receptors, while the family of TLR3, TLR7, 163 TLR8 and TLR9 are intracellular receptors located in endosomal com- 164 partments and responsible for the recognition of nucleic acids derived 165 from viruses, bacteria and the host [32-35]. TLR4 can recognize lipo- 166 polysaccharides (LPSs), which is the typical endotoxin for gram- 167 negative bacteria. The LPS-mediated inflammatory responses conse- 168 quently induce overexpression of miR-146a/b, miR-132 and miR-155. 169 Upregulation of miR-146 leads to translational repression of its target 170 genes interleukin-1 receptor-associated kinase (IRAK) 1 and tumor ne- 171 crosis factors receptor associated factor (TRAF) 6 [36]. miR-146 was rec- 172 ognized as a negative regulator of RLRs in the in vitro model of mouse 173 macrophages through targeting IRAK1, IRAK2 and TRAF6 [37]. Exposure 174 to LPS stimulates tumor necrosis factors (TNF)- $\alpha$ secretion. Overexpres- 175 sion of miR-155 and lower expression of miR-125b may relate with el- 176 evated level of TNF- $\alpha$. It was indicated that miR-155 targets transcript 177 coding gene for several proteins enhancing TNF- $\alpha$ translation, including 178 Fas-associated death domain protein (FADD), IkappaB kinase epsilon 179 (IKKepsilon) and TNFR superfamily-interacting serine-threonine ki- 180 nase 1 (Ripk1), while miR-125b targets the 3'-UTR of TNF- $\alpha$ transcripts 181 [38]. In miR-147 knockout mice, increased inflammatory cytokine ex- 182 pression found in macrophages upon TLR stimulation such as ligands 183 to TLR2, TLR3 and TLR4. Thus miR-147 was regarded as a negative reg- 184 ulator in TLR-activated inflammatory responses [39]. The miR-1303 185 production is also regulated by the NF- $\kappa B$ pathway. A recent study re- 186 vealed negative regulation of mycobacteria-induced Atg2B protein pro- 187 duction related with autophagy process [40].

188

The miR-146a and miR-155 influence IFN-type I synthesis in 189 plasmacytoid dendritic cells mediated by TLR-7 and TLR-9, while in T 190 and B cells, group of miRNAs including miR-21, miR-126, miR-146a, 191 miR-155, miR-1246 and others might correlate with epigenetic 192 


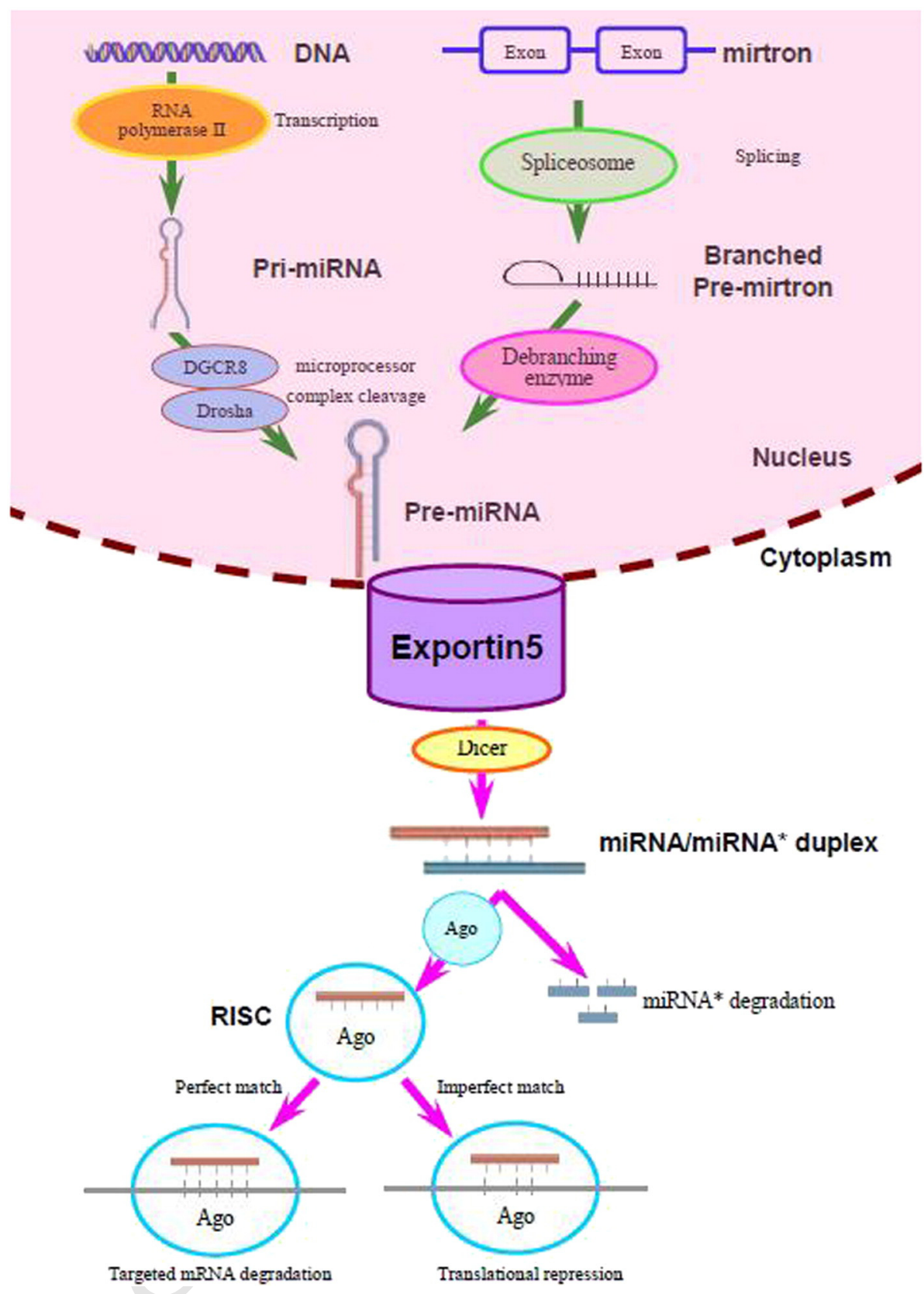

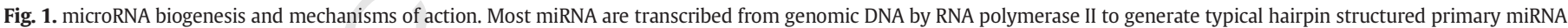

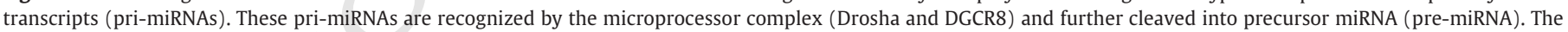

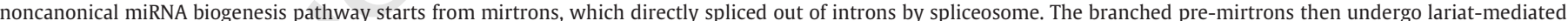

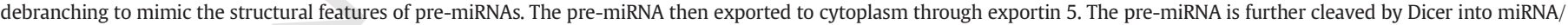

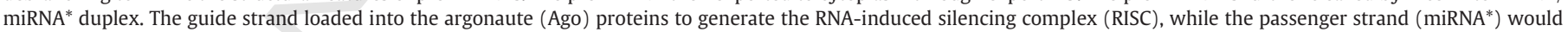

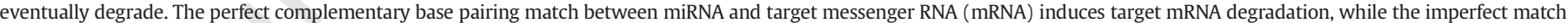
results in the repression of the mRNA translation.

modifications, support abnormal cytosine release, differentiation of cell subsets, B cell hyperactivity and autoantibody production [41].

\subsection{Adaptive immunity}

The adaptive immune system involved both $\mathrm{T}$ and $\mathrm{B}$ lymphocytes as major cellular components. One of the RNase III family enzymes, Dicer as mentioned previously is important in the biogenesis of miRNA. In the early stage of $\mathrm{T}$ cell development, depletion of Dicer leads to reduction of $\mathrm{T}$ cell numbers both in the thymus and peripheral lymphoid organs [42]. Dicer-deficient T helper (Th) cells show aberrant cytokine secretion, such as increased expression of IFN- $\gamma$ in the absence of exogenous cytokines and blocking antibodies [43]. In early B cell progenitors, depletion of Dicer results in blocking at the pro- to pre-B cell transition 204 since miR-17 mostly target the genes that upregulated in Dicer- 205 deficient pro-B cells [44].

Interleukin (IL)-17 produced by Th17 cells are closely related to 207 miR-326 and miR-155. It is shown that overexpression of miR-326 re- 208 sults in increased number of Th17 cells through targeting Ets-1 in mul- 209 tiple sclerosis patients and severe experimental autoimmune 210 encephalomyelitis (EAE) mice [45]. MiR-155 on the other hand is essen- 211 tial for dendritic cell production of cytokines which induce Th17 cell for- 212 mation. Mir-155 knockout mice are recognized resistant to EAE [46]. 213 MiR-155 is down-regulated in human monocyte-derived dendritic 214 cells in response to LPS-induced inflammatory processes [47]. MiR- 215 155 expression is necessary for maintaining regulatory T (Treg) cell 216 
t1.1 Table 1

t1.2 Differential expression of miRNAs in autoimmune diseases.

$\mathrm{t} 1.3$

$\mathrm{t} 1.4$

$\mathrm{t} 1.5$

t1.6

t1.7

$\mathrm{t} 1.8$

miR-155

SGECS $\quad$ miR-16

PBMCS miR-223

miR-483-5p

MiR-146a/b

miR-155

miR-181a

miR-34b-3p

miR-300

miR-609

miR-877-3p

miR-3162-3p

miR-4701-5p

RA PBMCs

miR-146a

MiR-301a-3p

Serum

miR-223

[74]

[77]

[78]

Table 1 (continued)

\begin{tabular}{|c|c|c|c|c|c|}
\hline \multirow{3}{*}{$\begin{array}{l}\text { Disease } \\
\text { Psoriasis }\end{array}$} & \multirow{3}{*}{$\begin{array}{l}\text { Sample } \\
\text { PBMCs }\end{array}$} & \multicolumn{4}{|c|}{ miRNA expression } \\
\hline & & \multicolumn{2}{|l|}{ Up-regulated } & \multicolumn{2}{|c|}{ Down-regulated } \\
\hline & & miR-142-3p & [119] & miR-99a & [119] \\
\hline & & miR-146a & & miR-125b & \\
\hline & & miR-155 & & miR-181a & \\
\hline & & miR-224 & & & \\
\hline & & miR-378 & & & \\
\hline & Serum & miR-146a & [120] & & \\
\hline & Th17 & miR-223 & [119] & miR-193b & [119] \\
\hline & Hair shaft & miR-424 & [121] & & \\
\hline & Lesional skin & miR-26b-5p & [122] & & \\
\hline
\end{tabular}

\section{Abbreviations}

SLE: systemic lupus erythematosus.

APS: antiphospholipid syndrome.

SS: Sjögren's syndrome.

RA: rheumatoid arthritis.

SSc: systemic sclerosis.

MS: multiple sclerosis.

PBMCs: peripheral blood mononuclear cells.

MSGs: minor salivary glands.

SGECs: salivary gland epithelial cells.

FFPE: formalin-fixed paraffin-embedded synovial tissue.

CSF: cerebral spinal fluid.

Th: T helper cell.

[71]

miR200b-5p [69]

miR-155

[76]

proliferative activity under Foxp3 regulation in controlling the IL-2 sig- 217 naling pathway by targeting the suppressor of cytokine signaling 218 (SOCS) 1 [48]. Like miR-155, miR-146a is not only relevant to the innate 219 immune system but also critical in the adaptive immune system. Over- 220 expression of miR-146a was found in Treg cells as a response to 221 activation of signal transducer and activator transcription (STAT) 1. 222 The negative regulator of STAT1 phosphorylation downstream 223 of the IFN- $\gamma$ receptor is SOCS1, which additionally associated with 224 Th1-mediated autoimmunity [49]. In activated B cells, miR-181b results 225 in the down-regulation of activation-induced cytidine deaminase (AID) 226 mRNA and protein levels. By restricting AID activity, miR-181b may pre- 227 vent $B$ cell malignant transformation [50].

The overexpression of miR-148a results in impaired B cell tolerance, 229 which accelerates the development of autoimmune diseases. Moreover, 230 miR-148a inhibits the expression of the autoimmune suppressor 231 Gadd $45 \alpha$, the tumor suppressor phosphatase and tensin homolog 232 (PTEN) and the pro-apoptotic protein Bim and protects immature B 233 cells from apoptosis induced by engagement of B cell antigen receptor 234 [51].

\section{MiRNAs in autoimmune diseases}

Alterations in miRNA regulation seem to be highly related to the de- 237 velopment of immune dysfunctions and autoimmunity. Recently sever- 238 al studies have focused on the role of miRNAs in autoimmune diseases 239 and different expression profiles have been identified as biomarkers of 240 certain autoimmune conditions, such as SLE, RA and SS. Table 1 summa- 241 rized the differential expression of miRNAs in autoimmune diseases. 242

\subsection{Systemic lupus erythematosus}

243

SLE is one of the most prevalent systemic autoimmune disorders. 244 SLE has a large spectrum of clinical presentations since the disease can 245 affect multiple organs, including skin, joints, kidneys, lungs, nervous 246 system, and serous membranes. The diversity of its clinical features is 247 matched by the complexity of pathogenic factors including genetic, 248 hormonal, and environmental factors [52].

A recent study demonstrated that blood plasma level of miRNA-126 250 was significantly lower in SLE patients compared to that in normal con- 251 trols. In addition, both plasma levels of IFN- $\alpha$ and interferon-inducible 252 gene ISG56 mRNA in peripheral blood mononuclear cells (PBMCs) 253 showed higher levels in SLE patients compared to controls. Based on 254 
these observations, miRNA-126 may inhibit the production of IFN- $\alpha$ and decrease in its expression level is possibly involved in the pathogenesis of SLE [53].

Zhu et al. reported high expression levels of miRNA-516a-3p, miRNA-629 and miRNA-525-5p in the PBMCs of paediatric SLE (pSLE) patients compared to healthy children. In addition, the increased expression levels of these three miRNAs were positively correlated with the SLEDAI scores and CRP levels. The target genes of these three miRNAs, namely Yinyang1 (YY1), Kruppel-like factor 13 (KLF13) and interferon regulatory factor 5 (IRF5), were found to be important in the pathogenesis of pSLE [54]. Dai et al. indicated 16 miRNAs with altered expression pattern in PBMCs, based on a microarray analysis involving 23 SLE patients from Han population, as following: seven miRNAs are decreased expression in SLE: miR-17-5p, miR-112, miR141, miR-184, miR-196a, miR-383, and miR-409-3p; the other nine miRNAs are overexpressed in SLE: miR-21, miR-61, miR-78, miR-1423p, miR-189, miR-198, miR-298, miR-299-3p, and miR-342 [55]. Two years later, they analyzed miRNAs in kidney biopsy samples of class II lupus nephritis (LN) patients, compared to renal tumor patients' kidney resection samples. They reported 66 miRNAs differentially regulated in lupus nephritis patients. Among them, 36 are up-regulated and the rest 30 are down-regulated [56].

The downregulation of miR-146a also contributes to the development of SLE. It was revealed that miR-146a is a negative regulator of type I IFN pathway by targeting IFN regulatory factor 5, STAT 1, IRAK1 and TRAF6 [57]. Two recent studies focused on miR-155; the miR-155 expression level correlated negatively with the expression of CD1d in B cells of SLE mice. Additionally, it was found that lower expression level of CD1d on B cells was decreased by targeting Ets-1 through activation of TLR9. Moreover, in juvenile SLE patients, miR-155 is downregulated in PBMCs compared to that of healthy controls. It was reported that miR-155 expression level was negatively correlated with Systemic Lupus Erythematosus Disease Activity Index (SLEDAI) score [58,59].

It is observed that up-regulation of miR-410 significantly reduced the expression levels of fibrosis factors such as transforming growth factor- $\beta 1$ (TGF- $\beta 1$ ) by inhibiting secretion of IL- 6 in the pathogenesis of LN [60]. The epigenetic modulator EZH2 might shift implicating effector in lupus naïve CD4 + T cells and opposes inhibitory TGF- $\beta$ signaling. The expression level of miR-26a, which is sensitive to glucose availability and targets EZH2, correlated negatively with SLEDAI [61].

A current study indicated that miR-148a-3p expression level was significantly higher in blood serum and glomerular cells in SLE with active LN. Up-regulation of miR-148a-3p accelerated glomerular cell proliferation and proliferating cell nuclear antigen (PCNA) expression, consequently reducing the PTEN expression level [62]. The significant overexpression of miR-130b-3p was demonstrated in serum of SLE patients with early stage LN, compared with that measured in healthy controls. Serum miR-130b-3p did not affect SLE disease activity (SLEDAI, ds-DNA, and complements levels) but correlated with renal damage since the expression of serum miR-130b-3p correlated positively with 24-h proteinuria and chronicity index (histological chronicity index and glomerular sclerosis) [63]. On the other hand, miR-29c expression in urinary exosomes showed a strong negative correlation with the chronicity but not with renal function (eGFR and creatinine levels). Urinary exosomes are micro-vesicles released by the epithelial cell facing the urinary space and proposed a novel and ideal source of markers for evaluating stage of LN [64]. Furthermore, expressions of several miRNAs were elevated in the urinary exosome fraction compared to the cell-free and exosome-depleted supernatant fraction, especially with LN. Among the exosomal miRNAs, miR-146a was the most overexpressed in SLE patients with active LN compared to the control group or to the SLE patients in the absence of LN [65].

Circulating antiphospholipid antibodies (aPLs) increase the risk of pregnancy complications, which leads to an autoimmune disorder named antiphospholipid syndrome (APS). APS patients with adverse pregnancy outcomes showed significantly higher levels of circulating exosomal-associated miR-146a-3p compared to healthy pregnant con- 321 trols. The specific aPL significantly induced trophoblasts to express 322 higher level of miR-146a-5p, miR-146a-3p, miR-155 and miR-210. Ex- 323 cept miR-155, the other miRNAs were inhibited by the TLR4 antagonist. 324 The suppression of miR-146a-3p significantly reduced aPL-induced tro- 325 phoblast IL-8 secretion regulated by the TLR8 [66].

\subsection{Primary Sjögren's syndrome}

Primary SS is a slowly progressive systemic autoimmune inflamma- 328 tory disease that primarily affects middle-aged women (female to male 329 ratio: 9:1), although it may be found in all ages including childhood. The 330 target organs are primarily exocrine glands, such as salivary and lachry- 331 mal glands. Therefore, patients show typically symptoms of dry mouth 332 and dry eyes [67]. Besides the pathognomonic glandular symptoms 333 (GS), other systemic symptoms, denoted as extraglandular manifesta- 334 tions (EGMs) (e.g. polyarthritis, myositis, vasculitis, polyneuropathy 335 etc.) can also develop during the disease course in approximately one 336 third of the patients [68].

The increase of Ro/SSA and La/SSB autoantigens is a common feature 338 in SS patients. The miRNAs which are suspected to target Ro/SSA and 339 La/SSB mRNAs in primary SS are as follows: let-7b, miR-16, miR-181a, 340 miR-200b-3p, miR-200b-5p, miR-223 and miR483-5p. The overexpres- 341 sion of miR-16 in minor salivary glands (MSGs), miR-200b-3p in 342 salivary gland epithelial cells (SGECs) and miR-223 together with 343 miR-483-5p in PBMCs of 29 SS patients compared to 24 sicca- 344 complaining controls has been shown previously. Significant lower- 345 expression of miR200b-5p levels was reported in SS patients with 346 mucosa-associated lymphoid tissue (MALT) lymphoma compared to 347 primary SS patients [69]. Another study demonstrated the positive cor- 348 relation between the expression levels of La/SSB and the Dicer enzyme 349 in connection with cancer prognosis. La/SSB promotes global microRNA 350 expression and identifies stem-loop [70]. Alevizos et al. generated 351 microRNA microarray profiles from the minor salivary glands of pa- 352 tients with SS who had low-grade or high-grade inflammation and im- 353 paired or normal saliva production, and compared the results with that 354 observed in healthy control subjects. They found hsa-miR-768-3p over- 355 expression, while hsa-miR-574 was underexpressed in patients' biop- 356 sies; additionally, their inverse correlations to focus scores were also 357 demonstrated [71]. Previously, our workgroup not only confirmed the 358 over-expression of miR-146a/b in PBMCs of SS but also demonstrated 359 the unanticipated over-expression of its functionally targeted gene, 360 TRAF 6. Furthermore, we also reported decreased gene expression of 361 IRAK 1 [72]. The over-expression of TRAF6 is surprising since miR- 362 146a could inhibit the expression of TRAF6 [73]. Recently, enhanced ex- 363 pression of miRNA-155 was reported in untreated Sjögren's syndrome 364 [74]. Of note, SS patients treated with immunosuppressants also 365 showed the over expression of miR-155. On the contrary, in Asian pop- 366 ulation the relative expression of miR-155 was lower in PBMCs of SS pa- 367 tients not receiving any immunosuppressive treatment than the 368 controls, which may emphasize the importance of the diverse genetic 369 background of different ethnicities [75,76]. A recent study demonstrat- 370 ed the over-expression of miR-181a in the PBMCs of pSS patients, which 371 was associated with the up-regulation of several virus-derived miRNAs, 372 suggesting that viral infection of PBMC plays a role in the disease [77]. 373

Up-regulated expression of miR-34b-3p, miR-4701-5p, miR-609, 374 miR-300, miR-3162-3p, and miR-877-3p in SS monocytes compared 375 to controls may relate with opposing of TGF- $\beta$ signaling pathway and 376 TLR/NF-KB pathways induced pro-inflammatory IL-12 secretion [78]. $\quad 377$

\subsection{Rheumatoid arthritis}

RA is a frequent autoimmune disorder with prevalence rates approx- 379 imately $1 \%$ of the adults worldwide. The disease primarily affects the 380 synovial joints, and the chronic inflammatory process consequently 381 causes the destruction of the articular tissue [79]. 
Associations between the alterations in miRNA expressions and the pathomechanisms of the disease have been shown previously. Elevated expression of miR-146a and miR-155 was determined both in whole blood samples and PBMCs of RA in Canadian cohort in comparison with healthy individuals [80]. The expression of the transcription factors (ROR $\gamma \mathrm{t}$ and STAT3) of Th17 cells was significantly increased in the PBMCs of RA patients while miR-301a-3p was also found overexpressed. Levels of miR-301a-3p showed positive correlation with the frequency of Th17 cells in RA patients [81]. MiR-146a, miR155 and miR-16 were found to have lower expression levels in the serum of early stage of RA patients who were prior to and after 3 and 12 months of antirheumatic drugs therapy compared to established RA. Based on a recent observation, miR-223 may be a potential marker of disease activity since decreased serum level of miR-223 was found after therapy in early RA [82].

MiR-16, miR-132, miR-146a, and miR-223 were found to be overexpressed in synovial fluid and blood plasma of patients compared to healthy controls. No correlation was identified between plasma and synovial fluid miRNAs although concentrations of miRNAs in synovial fluid were significantly lower compared to that of plasma levels [83]. A very recent study showed altered expression levels of certain miRNAs in formalin-fixed paraffin-embedded synovial tissue (FFPE) samples of patients with RA compared to osteoarthritis (OA) patients. It was reported that miR-146a, miR-155, and miR-223 were upregulated significantly in FFPE samples of established RA patients [84].

It was also shown that miR-188-5p is downregulated in synovial tissue samples of RA patients as well as in RA synovial fibroblasts (RASF). Moreover, it was revealed, that miR-188-5p is directly and indirectly regulating the expression of genes confirmed by gene expression profiling in RASF, including hyaluronan binding protein KIAA1199 as well as collagens COL1A1 and COL12A1, which may correlate with extracellular matrix formation and destruction in RA [85].

MiR-573 might be a negative regulator in RA since miR-573 could suppress the activation of mitogen-activated protein kinase (MAPK) which is regarded as one of the potential targets for RA treatment [86].

Regarding CD4 + T cells of RA patients, miRNA expression analysis indicated significant upregulation of miR-146a expression, while miR363 and miR-498 were downregulated [87].

The miRNA expression in macrophages from patients with active RA and OA was recently determined. Seven miRs, namely miR-99a, miR100, miR-125b, miR-199-3p, miR-199-5p, miR-152 and miR-214 were downregulated and only miR-223 was upregulated in macrophages in RA, compared to the results from OA samples. It was also implied that high miR-223 levels functionally impair the AHR (aryl hydrocarbon receptor)/ARNT (AHR nuclear translocator) pathway in myeloid cells by reducing ARNT protein levels. The AHR activation may be linked to the pathogenesis of RA, since AHR agonists inhibit pro-inflammatory cytokine expression in macrophages [88].

A recent study investigated single nucleotide polymorphisms (SNP) rs22928323 of miR-149 in 200 RA patients and 120 healthy controls. Rs22928323 showed correlation with RA development but was not associated with further clinical characteristics [89].

\subsection{Systemic sclerosis}

SSc is characterized by accelerated fibrosis and tissue damages in the skin and visceral organs such as heart, lungs and kidneys. SSc can be classified into two sub-groups based on the extent of skin thickening: limited SSc and diffuse SSc. Patients with the limited form are at lower risk of having visceral involvement, while the diffuse form involves several systems of internal organs [90].

Different study groups reported how miRNAs regulate fibrogenesis. The miR-15b, miR-16, miR-27a, miR-27b, miR-132, miR-150, and miR335 seem to play an important role in the induction of myofibroblast proliferation and resistance to apoptosis [91-98]. On the contrary,
miR-21, miR-92a, miR-133, miR-142-3p, miR-200a/b, and miR-590 446 have been shown to suppress fibrotic processes [99-105]. 447

Regarding other miRNAs, miR-29a was considered as the most direct 448 regulator of extracellular matrix (ECM) synthesis. It targets the gene 449 TAB1 and may lead to apoptosis of the dermal fibroblasts resulting to 450 lower TIMP-1 production and promote collagen degradation by increas- 451 ing MMP-1 production, suggesting that miR-29a may be a potential 452 therapeutic target for SSc [106]. The restoration of miR-29a decreased 453 TNF- $\alpha$ production in dermal fibroblasts of SSc patients. Moreover, Bcl-2 454 expression was upregulated in SSc fibroblasts and the ratio of Bax:Bcl-2 455 in fibroblasts was significantly lower compared to normal controls. How- 456 ever, miR-29a disrupted the expression profiling of Bcl-2 family proteins 457 (Bax, Bcl-2 and Bcl-XL), which proved that miR-29a is an anti-fibrotic 458 factor induce apoptosis and an attenuator cause ECM production in SSc 459 fibroblasts [107].

Additionally, miR-135b expression is significantly lower both in 461 serum and isolated CD14 + monocytes from patients compared to 462 controls. T cell-derived IL-13 increased collagen expression in dermal 463 fibroblasts which was dependent on STAT6 and miR-135b. Besides, 464 miR-135b is repressed by methylation and could be mediated by the re- 465 pressive protein methyl cap binding protein 2 (MeCP2), which is signif- 466 icantly enhanced in SSc dermal fibroblasts compared to controls [108]. 467

Iwamoto et al. reported the downregulation of miR-193b in SSc fi- 468 broblasts and skin sections. Knockdown of miR-193b induced the ex- 469 pression of mRNA and urokinase-type plasminogen activator (uPA) 470 enzyme, which was strongly expressed in vascular smooth muscle 471 cells in SSc skin section and contributed to the proliferative vasculopa- 472 thy with intimal hyperplasia characteristic for SSc [109].

\subsection{Multiple sclerosis}

Multiple sclerosis is an autoimmune neurological disease which af- 475 fects the brain and the spinal cord thus leading to the main triad symp- 476 toms of inflammation, demyelination and gliosis. The damage of the 477 protective covering of the myelin sheath surrounding the nerve cells re- 478 sult in single or multiple symptoms including motoric, speech, 479 swallowing, and visual disabilities and other neuronal problems [110]. 480

MiR expression profile analysis indicated significant overexpression 481 of miR-21, miR-146a, miR-146b and miR-155 in PBMCs of relapsing re- 482 mitting MS patients compared to controls [111,112]. MiR-326 promotes 483 differentiation by targeting Ets-1, furthermore, its overexpression leads 484 to Th17 cell proliferation and disease aggravation in experimental 485 autoimmune encephalomyelitis [113]. Upregulation of miR-27a was 486 observed in relapsing phase of MS compared to remitting phase and 487 healthy controls; on the contrary, miR-214 was underexpressed in 488 relapsing phase of MS, which implied that miR-27a may inhibit 489 Th17 cell differentiation, while miR-214 may promote Th17 cell 490 differentiation [114].

The expression of miR-140-5p was found to be significantly de- 492 creased in the PBMCs of MS patients compared to those in controls, 493 and miR-140-5p level was inversely correlated with disease severity. 494 Transfection of synthetic miR-140-5p in PBMCs inhibited activation of 495 STAT1 and consequently suppressed the encephalitogenic Th1 differen- 496 tiation, which suggests that miR-140-5p may be a novel marker in- 497 volved in the pathogenesis of MS [115].

Another group recently reported significantly lower expression of 499 miR-572 in overall MS patients, compared to healthy controls. MiR- 500 572 was found to be significantly upregulated in secondary progressive 501 and relapsing remitting MS, while it was downregulated in primary pro- 502 gressive MS. Consequently, with the different potential, this miRNA 503 could be regarded as a non-invasive biomarker for remyelination [116]. 504

The expression level of miR-150 was elevated in cerebral spinal fluid 505 (CSF) from patients with clinically isolated syndrome (CIS) who convert 506 to MS later, compared to those CIS who did not convert during follow- 507 up (median period of 52 months). The miR-150 may be regarded as a 508 marker of CNS inflammation, since higher levels of miR-150 correlate 509 
with higher levels of CSF biomarkers, involving C-X-C motif chemokine 13 (CXCL13), matrix metallopeptidase 9 (MMP-9) and osteopontin. Additionally, the level of miR-150 in CSF decreased after treating with natalizumab for one year and remains unchanged with fingolimod, while level of miR-150 in plasma increased after the treatment with natalizumab and decreased after fingolimod therapy [117].

\subsection{Psoriasis}

Psoriasis is a chronic and frequently relapsing inflammatory skin disease characterized by pathologic features such as accelerated epidermopoiesis, marked hyperkeratosis with parakeratosis, vascular dilatation, and inflammatory cell infiltration. The most common form of the disorder is the chronic plaque psoriasis with rounded erythematous, dry, scaling patches. The lesions have a predilection site as nails, scalp, genitalia, extensor surfaces, and the lumbosacral region [118].

Recently, a study group discovered 24 dysregulated miRNAs in the epidermis of psoriatic skin and 37 dysregulated miRNAs in the dermal inflammatory infiltrates of patients. Among those, miR-99a, miR-125b and miR-181a were significantly lower expressed in PBMCs while miR-142-3p, miR-146a, miR-155, miR-224 and miR-378 were upregulated. Moreover, miR-193b was downregulated and miR-223 was upregulated in Th17 cells, while miR-125b was downregulated in T regulatory cells [119]. MiR-146a level was up-regulated in blood samples from patients of psoriasis in comparison with healthy controls, but no significant positive relation was revealed with PASI scores in patients. However after 12 weeks of treatment with Narrow-Band Ultraviolet B phototherapy or treatment with methotrexate, expression of miR-146a decreased dramatically, which suggests that miR-146a may be useful in evaluating and screening the effect of treatment of psoriasis objectively [120].

Even though miR-424 levels were not correlated with disease activity markers, such as PASI (psoriasis area and severity index), hair shaft; miR-424 levels were significantly upregulated in psoriasis patients compared with normal controls and those with atopic dermatitis [121].

A recent study reported increased level of miR-26b-5p in subcutaneous adipose tissue under lesional psoriasis skin compared to nonlesional psoriatic skin. miR-26b-5p down-regulates neutral cholesterol ester hydrolase 1 enzyme, which is essential for cholesterol efflux, in monocytes/macrophages, adipocytes, vascular endothelial cells and fibroblasts [122].

Additionally, the G allele of SNP rs2910164 in miR-146a regarded as a risk factor, which would impair its suppression on the proliferation of keratinocytes through the decreased inhibition of the target gene [123].

\section{Conclusions and future perspectives}

The discovery of miRNAs and the recognition of their critical role in modulating gene expression changed the way we think about genetic control. The intensive research over the last decade shed light on multiple pathways and modes how miRNAs regulate cell development and differentiation. The central role of miRNAs in modulating immune system responses was also recognized, although, there are numerous questions about miRNAs, yet to be answered.

In the last years much attention was drawn to the function of miRNAs in autoimmunity. Changes in the expression levels of certain miRNAs in the circulation or in different cells and tissues are characteristics for various autoimmune conditions and presumably contribute to disease development. Consequently, some of these molecules may be regarded as novel and attractive biomarkers specific for different autoimmune disorders. However, functional experimental studies are required to verify and establish the causal association between the aberrantly expressed miRNAs and the development of disease. Additionally, the mechanisms underlying the aberrant expression of miRNAs, as well as the influence of other factors that regulate miRNAs, also remained to be investigated.
Genome-wide surveys identified many single nucleotide polymor- 572 phisms (SNPs) in the predicted miRNA target sites, as well as in miRNAs 573 themselves. In some instances, SNPs have been shown to alter miRNA 574 function, thus possibly contributing to disease development. The better 575 understanding of the immune regulatory mechanisms of miRNAs by 576 pathway-based exploratory analyses and the mapping and characteri- 577 zation of miRNA SNPs may help not only to elucidate the pathogenesis 578 of autoimmune conditions but also can lead to the development of com- 579 plex therapeutic approaches in patients with immunological disorders. 580

\section{Take-home messages}

- Alterations of miRNAs expression are involved in the development of 582 autoimmune conditions.

- Certain miRNAs could be regarded as novel and specific biomarkers 584 for different autoimmune diseases.

- Exploration of miRNA target genes will define their role in autoimmu- 586 nity and reveal novel targets and therapeutic approaches.

\section{Conflict of interest}

No disclosure to report.

\section{Acknowledgments}

This work was supported by the Chinese Scholarship Council, the Q3 grants of the Hungarian National Scientific Research Fund (OTKA) and 595 TÁMOP-4.2.2.A-11/1/KONV-2012-0023 project, which is co-financed 596 by the European Union and European Social Fund.

\section{References}

11] Chua JH, Armugam A, Jeyaseelan K. MicroRNAs: biogenesis, function and applications. 599 Curr Opin Mol Ther 2009;11:189-199.

[2] Bartel DP. MicroRNAs: genomics, biogenesis, mechanism, and function. Cell 2004;116: 601 281-297.

[3] Wang H, Peng W, Ouyang X, Li W, Dai Y. Circulating microRNAs as candidate biomarkers 603 in patients with systemic lupus erythematosus. Transl Res 2012;160:198-206. http://dx. 604 doi.org/10.1016/j.trsl.2012.04.002.

[4] Kapsogeorgou EK, Gourzi VC, Manoussakis MN, Moutsopoulos HM, Tzioufas AG. Cellular 606 microRNAs (miRNAs) and Sjögren's syndrome: candidate regulators of autoimmune re- 607 sponse and autoantigen expression. J Autoimmun 2011;37:129-135. http://dx.doi.org/ 608 10.1016/j.jaut.2011.05.003.

[5] Furer V, Greenberg JD, Attur M, Abramson SB, Pillinger MH. The role of microRNA in rheu- 610 matoid arthritis and other autoimmune diseases. Clin Immunol 2010;136:1-15. http://dx. 611 doi.org/10.1016/j.clim.2010.02.005.

[6] Lee Y, Kim M, Han J, Yeom K-H, Lee S, Baek SH, et al. MicroRNA genes are transcribed by 613 RNA polymerase II. EMBO J 2004;23:4051-4060, http://dx.doi.org/10.1038/sj.emboj. 614 7600385.

[7] Cullen BR. Transcription and processing of human microRNA precursors. Mol Cell 2004; 616 16:861-865. http://dx.doi.org/10.1016/j.molcel.2004.12.002. 617

[8] Cai X, Hagedorn $\mathrm{CH}$, Cullen BR. Human microRNAs are processed from capped, 618 polyadenylated transcripts that can also function as mRNAs. RNA 2004;10:1957-1966. 619 http://dx.doi.org/10.1261/rna.7135204.

[9] Gregory RI, Yan K-P, Amuthan G, Chendrimada T, Doratotaj B, Cooch N, et al. The micro- 621 processor complex mediates the genesis of microRNAs. Nature 2004;432:235-240. 622 http://dx.doi.org/10.1038/nature03120. 623

[10] Lee Y, Ahn C, Han J, Choi H, Kim J, Yim J, et al. The nuclear RNase III Drosha initiates 624 microRNA processing. Nature 2003;425:415-419. http://dx.doi.org/10.1038/ 625 nature01957.

[11] Yi R, Oin Y, Macara IG, Cullen BR. Exportin-5 mediates the nuclear export of pre- 627 microRNAs and short hairpin RNAs. Genes Dev 2003;17:3011-3016. http://dx.doi.org/ 628 10.1101/gad.1158803.

[12] Ruby JG, Jan CH, Bartel DP. Intronic microRNA precursors that bypass Drosha processing. 630 Nature 2007;448:83-86. http://dx.doi.org/10.1038/nature05983.

[13] Okam 2007, Hen JW, Duan H, Tyler DM, Lai EC. The microRNA-class regulatory RNAs in Drosophila. Cell 2007;130:89-100. http://dx.doi. 633 org/10.1016/j.cell.2007.06.028.

[14] Berezikov E, Chung W-J, Willis J, Cuppen E, Lai EC. Mammalian mirtron genes. Mol Cell 635 2007:28:328-336. http://dx.doi.org/10.1016/j.molcel.2007.09.028. 636

[15] Park J-E, Heo I, Tian Y, Simanshu DK, Chang H, Jee D, et al. Dicer recognizes the $5^{\prime}$ end of 637 RNA for efficient and accurate processing. Nature 2011;475:201-205. http://dx.doi.org/ 638 10.1038/nature10198.

[16] Lund E, Dahlberg JE. Substrate selectivity of exportin 5 and Dicer in the biogenesis of 640 microRNAs. Cold Spring Harb Symp Quant Biol 2006;71:59-66. http://dx.doi.org/10. 641 1101/sqb.2006.71.050.

[17] Yoda M, Cifuentes D, Izumi N, Sakaguchi Y, Suzuki T, Giraldez AJ, et al. Poly(A)-specific 643 ribonuclease mediates 3'-end trimming of Argonaute2-cleaved precursor microRNAs. 644 Cell Rep 2013;5:715-726. http://dx.doi.org/10.1016/j.celrep.2013.09.029.

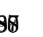

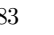
5

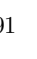
(1)

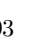

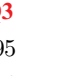

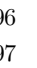
s. , 03 6
6 908 10 611 法 16 隹 .

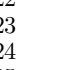
, 
[18] Fabian MR, Sonenberg N, Filipowicz W. Regulation of mRNA translation and stability by microRNAs. Annu Rev Biochem 2010;79:351-379. http://dx.doi.org/10.1146/annurevbiochem-060308-103103.

[19] Lewis BP, Burge CB, Bartel DP. Conserved seed pairing, often flanked by adenosines, indicates that thousands of human genes are microRNA targets. Cell 2005;120:15-20. http:// dx.doi.org/10.1016/j.cell.2004.12.035.

20] Carthew RW, Sontheimer EJ. Origins and mechanisms of miRNAs and siRNAs. Cell 2009; 136:642-655. http://dx.doi.org/10.1016/j.cell.2009.01.035.

[21] Valencia-Sanchez MA, Liu J, Hannon GJ, Parker R. Control of translation and mRNA degradation by miRNAs and siRNAs. Genes Dev 2006;20:515-524. http://dx.doi.org/10.1101/ gad.1399806.

[22] Meister G, Landthaler M, Patkaniowska A, Dorsett Y, Teng G, Tuschl T. Human Argonaute2 mediates RNA cleavage targeted by miRNAs and siRNAs. Mol Cell 2004;15:185-197. http://dx.doi.org/10.1016/j.molcel.2004.07.007.

[23] Pillai RS, Bhattacharyya SN, Filipowicz W. Repression of protein synthesis by miRNAs: how many mechanisms? Trends Cell Biol 2007;17:118-126. http://dx.doi.org/10.1016/ j.tcb.2006.12.007.

[24] Bruno I, Wilkinson MF. P-bodies react to stress and nonsense. Cell 2006;125:1036-1038. http://dx.doi.org/10.1016/j.cell.2006.06.003.

[25] Dai R, Ahmed SA. MicroRNA, a new paradigm for understanding immunoregulation, inflammation, and autoimmune diseases. Transl Res 2011;157:163-179. http://dx.doi. org/10.1016/j.trsl.2011.01.007.

[26] Gangaraju VK, Lin H. MicroRNAs: key regulators of stem cells. Nat Rev Mol Cell Biol 2009; 10:116-125. http://dx.doi.org/10.1038/nrm2621.

[27] Chen C-Z, Li L, Lodish HF, Bartel DP. MicroRNAs modulate hematopoietic lineage differentiation. Science 2004;303:83-86. http://dx.doi.org/10.1126/science. 1091903.

[28] Raghuwanshi S, Karnati HK, Sarvothaman S, Gutti U, Saladi RGV, Tummala PR, et al. microRNAs: key players in hematopoiesis. Adv Exp Med Biol 2015;887:171-211. http:// dx.doi.org/10.1007/978-3-319-22380-3_10.

[29] Akira S, Uematsu S, Takeuchi O. Pathogen recognition and innate immunity. Cell 2006; 124:783-801. http://dx.doi.org/10.1016/j.cell.2006.02.015

[30] Santegoets KC $\bar{M}$, van Bon L, van den Berg WB, Wenink MH, Radstake TRDJ. Toll-like receptors in rheumatic diseases: are we paying a high price for our defense against bugs? FEBS Lett 2011;585:3660-3666. http://dx.doi.org/10.1016/j.febslet.2011.04.028.

[31] Mogensen TH, Paludan SR. Reading the viral signature by Toll-like receptors and other pattern recognition receptors. J Mol Med (Berl) 2005;83:180-192. http://dx.doi.org/10. 1007/s00109-004-0620-6.

[32] Kawai T, Akira S. Toll-like receptors and their crosstalk with other innate receptors in infection and immunity. Immunity 2011;34:637-650. http://dx.doi.org/10.1016/j.immuni. 2011.05.006.

[33] Roach JC, Glusman G, Rowen L, Kaur A, Purcell MK, Smith KD, et al. The evolution of vertebrate Toll-like receptors. Proc Natl Acad Sci U S A 2005;102:9577-9582. http://dx.doi. org/10.1073/pnas.0502272102.

[34] Takeda K, Akira S. Toll-like receptors in innate immunity. Int Immunol 2005;17:1-14. http://dx.doi.org/10.1093/intimm/dxh186.

[35] Chen J-Q, Szodoray P, Zeher M. Toll-like receptor pathways in autoimmune diseases. Clin Rev Allergy Immunol 2015. http://dx.doi.org/10.1007/s12016-015-8473-z.

[36] Taganov KD, Boldin MP, Chang K-J, Baltimore D. NF-kappaB-dependent induction of microRNA miR-146, an inhibitor targeted to signaling proteins of innate immune responses. Proc Natl Acad Sci U S A 2006;103:12481-12486. http://dx.doi.org/10.1073/ pnas.0605298103.

[37] Hou J, Wang P, Lin L, Liu X, Ma F, An H, et al. MicroRNA-146a feedback inhibits RIG-Idependent Type I IFN production in macrophages by targeting TRAF6, IRAK1, and IRAK2. J Immunol 2009;183:2150-2158. http://dx.doi.org/10.4049/jimmunol.0900707.

[38] Tili E, Michaille J-J, Cimino A, Costinean S, Dumitru CD, Adair B, et al. Modulation of miR155 and miR-125b levels following lipopolysaccharide/TNF-alpha stimulation and their possible roles in regulating the response to endotoxin shock. J Immunol 2007;179: 5082-5089.

[39] Liu G, Friggeri A, Yang Y, Park Y-J, Tsuruta Y, Abraham E. miR-147, a microRNA that is induced upon Toll-like receptor stimulation, regulates murine macrophage inflammatory responses. Proc Natl Acad Sci U S A 2009;106:15819-15824. http://dx.doi.org/10.1073/ pnas.0901216106.

[40] Au KY, Pong JCH, Ling WL, Li JCB. MiR-1303 regulates mycobacteria induced autophagy by targeting Atg2B. PLoS One 2016;11, e0146770. http://dx.doi.org/10.1371/journal.pone. 0146770 .

[41] Husakova M. MicroRNAs in the key events of systemic lupus erythematosus pathogenesis. Biomed Pap Med Fac Univ Palacky Olomouc Czech Repub 2016. http://dx.doi.org/ 10.5507/bp.2016.004.

[42] Cobb BS, Nesterova TB, Thompson E, Hertweck A, O'Connor E, Godwin J, et al. T cell lineage choice and differentiation in the absence of the RNase III enzyme Dicer. J Exp Med 2005;201:1367-1373. http://dx.doi.org/10.1084/jem.20050572.

[43] Muljo SA, Ansel KM, Kanellopoulou C, Livingston DM, Rao A, Rajewsky K. Aberrant T cell differentiation in the absence of Dicer. J Exp Med 2005;202:261-269. http://dx.doi.org/ 10.1084/jem.20050678

[44] Koralov SB, Muljo SA, Galler GR, Krek A, Chakraborty T, Kanellopoulou C, et al. Dicer ablation affects antibody diversity and cell survival in the B lymphocyte lineage. Cell 2008;132:860-874. http://dx.doi.org/10.1016/j.cell.2008.02.020.

[45] Du C, Liu C, Kang J, Zhao G, Ye Z, Huang S, et al. MicroRNA miR-326 regulates TH-17 differentiation and is associated with the pathogenesis of multiple sclerosis. Nat Immunol 2009;10:1252-1259. http://dx.doi.org/10.1038/ni.1798.

[46] O'Connell RM, Kahn D, Gibson WSJ, Round JL, Scholz RL, Chaudhuri AA, et al. MicroRNA155 promotes autoimmune inflammation by enhancing inflammatory $\mathrm{T}$ cell development. Immunity 2010;33:607-619. http://dx.doi.org/10.1016/j.immuni.2010.09.009.

[47] Ceppi M, Pereira PM, Dunand-Sauthier I, Barras E, Reith W, Santos MA, et al. MicroRNA155 modulates the interleukin-1 signaling pathway in activated human monocytederived dendritic cells. Proc Natl Acad Sci U S A 2009;106:2735-2740. http://dx.doi.org/ 10.1073/pnas.0811073106

[48] Lu L-F, Thai T-H, Calado DP, Chaudhry A, Kubo M, Tanaka K, et al. Foxp3-dependent microRNA155 confers competitive fitness to regulatory T cells by targeting SOCS1 protein. Immunity 2009;30:80-91. http://dx.doi.org/10.1016/j.immuni.2008.11.010.
[49] Lu L-F, Boldin MP, Chaudhry A, Lin L-L, Taganov KD, Hanada T, et al. Function of miR-146a 737 in controlling Treg cell-mediated regulation of Th1 responses. Cell 2010:142:914-929. 738 http://dx.doi.org/10.1016/j.cell.2010.08.012.

[50] de Yébenes VG, Belver L, Pisano DG, González S, Villasante A, Croce C, et al. miR-181b neg- 740 atively regulates activation-induced cytidine deaminase in B cells. J Exp Med 2008;205: 741 2199-2206. http://dx.doi.org/10.1084/jem20080579.

[51] Gonzalez-Martin A, Adams BD, Lai M, Shepherd J, Salvador-Bernaldez M, Salvador JM, 743 et al. The microRNA miR-148a functions as a critical regulator of B cell tolerance and au- 744 toimmunity. Nat Immunol 2016;17:433-440. http://dx.doi.org/10.1038/ni.3385. 745

[52] Rothfield N. Clinical aspects and treatment of systemic lupus erythematosus. Curr Opin 746 Rheumatol 1989;1:327-331.

[53] Liu Y-J, Fan W-J, Bai J-Z. microRNA-126 expression and its mechanism of action in pa- 748 tients with systemic lupus erythematosus. Eur Rev Med Pharmacol Sci 2015;19: 749 3838-3842.

[54] Zhu J, Huang X, Su G, Wang L, Wu F, Zhang T, et al. High expression levels of microRNA- 751 629, microRNA-525-5p and microRNA-516a-3p in paediatric systemic lupus erythemato- 752 sus. Clin Rheumatol 2014;33:807-815. http://dx.doi.org/10.1007/s10067-014-2583-5. 753

[55] Dai Y, Huang Y-S, Tang M, Lv T-Y, Hu C-X, Tan Y-H, et al. Microarray analysis of microRNA 754 expression in peripheral blood cells of systemic lupus erythematosus patients. Lupus 755 2007;16:939-946. http://dx.doi.org/10.1177/0961203307084158. 756

[56] Dai Y, Sui W, Lan H, Yan Q Huang H, Huang Y. Comprehensive analysis of microRNA ex- 757 pression patterns in renal biopsies of lupus nephritis patients. Rheumatol Int 2009;29: 758 749-754. http://dx.doi.org/10.1007/s00296-008-0758-6. 759

[57] Tang Y, Luo X, Cui H, Ni X, Yuan M, Guo Y, et al. MicroRNA-146 A contributes to abnormal 760 activation of the type I interferon pathway in human lupus by targeting the key signaling 761 proteins. Arthritis Rheum 2009;60:1065-1075. http://dx.doi.org/10.1002/art.24436. 762

[58] Liu F, Fan H, Ren D, Dong G, Hu E, Ji J, et al. TLR9-induced miR-155 and Ets-1 decrease ex- 763 pression of CD1d on B cells in SLE. Eur J Immunol 2015;45:1934-1945. http://dx.doi.org/ 764 10.1002/eji.201445286.

[59] Lashine YA, Salah S, Aboelenein HR, Abdelaziz AI. Correcting the expression of miRNA- 766 155 represses PP2AC and enhances the release of IL-2 in PBMCs of juvenile SLE patients. 767 Lupus 2015;24:240-247. http://dx.doi.org/10.1177/0961203314552117.

[60] Liu D, Zhang $\mathrm{N}$, Zhang J, Zhao $\mathrm{H}$, Wang X. miR-410 suppresses the expression of 769 interleukin-6 as well as renal fibrosis in the pathogenesis of lupus nephritis. Clin Exp 770 Pharmacol Physiol 2016;43:616-625. http://dx.doi.org/10.1111/1440-1681.12576. 771

[61] Coit P, Dozmorov MG, Merrill JT, McCune WJ, Maksimowicz-McKinnon K, Wren JD, et al. 772 Epigenetic reprogramming in naïve CD4 + T cells favoring T cell activation and non-Th1 773 effector T cell immune response as an early event in lupus flares. Arthritis Rheumatol 774 2016. http://dx.doi.org/10.1002/art.39720.

[62] Qingjuan L, Xiaojuan F, Wei Z, Chao W, Pengpeng K, Hongbo L, et al. miR-148a-3p 776 overexpression contributes to glomerular cell proliferation by targeting PTEN in lupus 777 nephritis. Am J Physiol Cell Physiol 2016;310:C470-C478. http://dx.doi.org/10.1152/ 778 ajpcell.00129.2015.

[63] Wang W, Mou S, Wang L, Zhang M, Shao X, Fang W, et al. Up-regulation of serum 780 MiR-130b-3p level is associated with renal damage in early lupus nephritis. Sci Rep 781 2015;5:12644. http://dx.doi.org/10.1038/srep12644.

[64] Solé C, Cortés-Hernández J, Felip ML, Vidal M, Ordi-Ros J. miR-29c in urinary exosomes as 783 predictor of early renal fibrosis in lupus nephritis. Nephrol Dial Transplant 2015;30: 784 1488-1496. http://dx.doi.org/10.1093/ndt/gfv128.

[65] Perez-Hernandez J, Forner MJ, Pinto C, Chaves FJ, Cortes R, Redon J. Increased urinary 786 exosomal microRNAs in patients with systemic lupus erythematosus. PLoS One 2015; 787 10, e0138618. http://dx.doi.org/10.1371/journal.pone.0138618.

[66] Gysler SM, Mulla MJ, Guerra M, Brosens JJ, Salmon JE, Chamley LW, et al. 789 Antiphospholipid antibody-induced miR-146a-3p drives trophoblast interleukin-8 secre- 790 tion through activation of Toll-like receptor 8. Mol Hum Reprod 2016. http://dx.doi.org/ 791 10.1093/molehr/gaw027.

[67] Zeher M, Szodoray P. Sjögren's syndrome and associated disorders. vol. Sjögren's Syn- 793 drome. Kerala, India: Transworld Research Network; 2009.

[68] Szanto A, Szodoray P, Kiss E, Kapitany A, Szegedi G, Zeher M. Clinical, serologic, and genet- 795 ic profiles of patients with associated Sjögren's syndrome and systemic lupus erythema- 796 tosus. Hum Immunol 2006;67:924-930. http://dx.doi.org/10.1016/j.humimm.2006.06. 797 006.

[69] Gourzi VC, Kapsogeorgou EK, Kyriakidis NC, Tzioufas AG. Study of microRNAs (miRNAs) 799 that are predicted to target the autoantigens Ro/SSA and La/SSB in primary Sjögren's Syn- 800 drome. Clin Exp Immunol 2015;182:14-22. http://dx.doi.org/10.1111/cei.12664. 801

[70] Liang C, Xiong K, Szulwach KE, Zhang Y, Wang Z, Peng J, et al. Sjogren syndrome antigen B 802 (SSB)/La promotes global microRNA expression by binding microRNA precursors through 803 stem-loop recognition. J Biol Chem 2013;288:723-736. http://dx.doi.org/10.1074/jbc. 804 M112.401323.

[71] Alevizos I, Alexander S, Turner RJ, Illei GG. MicroRNA expression profiles as biomarkers of 806 minor salivary gland inflammation and dysfunction in Sjögren's syndrome. Arthritis 807 Rheum 2011;63:535-544. http://dx.doi.org/10.1002/art.30131.

[72] Zilahi E, Tarr T, Papp G, Griger Z, Sipka S, Zeher M. Increased microRNA-146a/b, TRAF6 809 gene and decreased IRAK1 gene expressions in the peripheral mononuclear cells of pa- 810 tients with Sjögren's syndrome. Immunol Lett 2012;141:165-168. http://dx.doi.org/10. 811 1016/j.imlet.2011.09.006

[73] Bhaumik D, Scott GK, Schokrpur S, Patil CK, Campisi J, Benz CC. Expression of microRNA- 813 146 suppresses NF-kappaB activity with reduction of metastatic potential in breast cancer 814 cells. Oncogene 2008;27:5643-5647. http://dx.doi.org/10.1038/onc.2008.171. 815

[74] Chen J-Q, Zilahi E, Papp G, Sipka S, Zeher M. Simultaneously increased expression of 816 microRNA-155 and suppressor of cytokine signaling 1 (SOCS1) gene in the peripheral 817 blood mononuclear cells of patients with primary Sjögren's syndrome. Int J Rheum Dis 818 2015. http://dx.doi.org/10.1111/1756-185X.12804.

[75] Pauley KM, Stewart CM, Gauna AE, Dupre LC, Kuklani R, Chan AL, et al. Altered miR-146a 820 expression in Sjögren's syndrome and its functional role in innate immunity. Eur J 821 Immunol 2011;41:2029-2039. http://dx.doi.org/10.1002/eji.201040757.

[76] Shi H, Zheng L, Zhang P, Yu C. miR-146a and miR-155 expression in PBMCs from patients 823 with Sjögren's syndrome. J Oral Pathol Med 2014;43:792-797. http://dx.doi.org/10.1111/ 824 jop.12187.

[77] Peng L, Ma W, Yi F, Yang Y-J, Lin W, Chen H, et al. MicroRNA profiling in Chinese patients 826 with primary Sjögren syndrome reveals elevated miRNA-181a in peripheral blood 827 
mononucle

78] Williams AEG, Choi K, Chan AL, Lee YJ, Reeves WH, Bubb MR, et al. Sjögren's syndromeassociated microRNAs in CD14(+) monocytes unveils targeted TGF 3 signaling. Arthritis Res Ther 2016;18:95. http://dx.doi.org/10.1186/s13075-016-0987-0.

[79] Gibofsky A. Overview of epidemiology, pathophysiology, and diagnosis of rheumatoid arthritis. Am J Manag Care 2012;18:S295-S302.

[80] Mookherjee N, El-Gabalawy HS. High degree of correlation between whole blood and PBMC expression levels of miR-155 and miR-146a in healthy controls and rheumatoid arthritis patients. J Immunol Methods 2013;400-401:106-110. http://dx.doi.org/10.1016/j. jim.2013.10.001

[81] Tang X, Yin K, Zhu H, Tian J, Shen D, Yi L, et al. Correlation between the expression of microRNA-301a-3p and the proportion of Th17 cells in patients with rheumatoid arthritis. Inflammation 2016. http://dx.doi.org/10.1007/s10753-016-0304-8.

[82] Filková M, Aradi B, Šenolt L, Ospelt C, Vettori S, Mann H, et al. Association of circulating miR-223 and miR-16 with disease activity in patients with early rheumatoid arthritis. Ann Rheum Dis 2014;73:1898-1904. http://dx.doi.org/10.1136/annrheumdis-2012202815.

[83] Murata K, Yoshitomi H, Tanida S, Ishikawa M, Nishitani K, Ito H, et al. Plasma and synovial fluid microRNAs as potential biomarkers of rheumatoid arthritis and osteoarthritis. Arthritis Res Ther 2010;12:R86. http://dx.doi.org/10.1186/ar3013.

[84] Kriegsmann M, Randau TM, Gravius S, Lisenko K, Altmann C, Arens N, et al. Expression of miR-146a, miR-155, and miR-223 in formalin-fixed paraffin-embedded synovial tissues of patients with rheumatoid arthritis and osteoarthritis. Virchows Arch 2016. http://dx. doi.org/10.1007/s00428-016-1939-4.

[85] Ruedel A, Dietrich P, Schubert T, Hofmeister S, Hellerbrand C, Bosserhoff A-K. Expression and function of microRNA-188-5p in activated rheumatoid arthritis synovial fibroblasts. Int J Clin Exp Pathol 2015;8:4953-4962.

[86] Wang L, Song G, Zheng Y, Wang D, Dong H, Pan J, et al. miR-573 is a negative regulator in the pathogenesis of rheumatoid arthritis. Cell Mol Immunol 2015. http://dx.doi.org/10. 1038/cmi.2015.63.

[87] Li J, Wan Y, Guo Q Zou L, Zhang J, Fang Y, et al. Altered microRNA expression profile with miR-146a upregulation in CD4 + T cells from patients with rheumatoid arthritis. Arthritis Res Ther 2010;12:R81. http://dx.doi.org/10.1186/ar3006.

[88] Ogando J, Tardáguila M, Díaz-Alderete A, Usategui A, Miranda-Ramos V, Martínez-Herrera DJ, et al. Notch-regulated miR-223 targets the aryl hydrocarbon receptor pathway and increases cytokine production in macrophages from rheumatoid arthritis patients. Sci Rep 2016;6:20223. http://dx.doi.org/10.1038/srep20223.

[89] Xiao M, Ma Y, Chen X, Kuang B. Single nucleotide polymorphism of miR-149 and susceptibility of rheumatoid arthritis. Zhong Nan Da Xue Xue Bao Yi Xue Ban 2015;40:495-498. http://dx.doi.org/10.11817/j.issn.1672-7347.2015.05.006.

[90] Casale R, Buonocore M, Matucci-Cerinic M. Systemic sclerosis (scleroderma): an integrated challenge in rehabilitation. Arch Phys Med Rehabil 1997;78:767-773.

[91] Chen C, Wu C-Q, Zhang Z-Q Yao D-K, Zhu L. Loss of expression of miR-335 is implicated in hepatic stellate cell migration and activation. Exp Cell Res 2011;317:1714-1725. http:// dx.doi.org/10.1016/j.yexcr.2011.05.001.

[92] Venugopal SK, Jiang J, Kim T-H, Li Y, Wang S-S, Torok NJ, et al. Liver fibrosis causes downregulation of miRNA-150 and miRNA-194 in hepatic stellate cells, and their overexpression causes decreased stellate cell activation. Am J Physiol Gastrointest Liver Physio 2010;298:G101-G106. http://dx.doi.org/10.1152/ajpgi.00220.2009.

[93] Guo C-J, Pan Q Li D-G, Sun H, Liu B-W. miR-15b and miR-16 are implicated in activation of the rat hepatic stellate cell: an essential role for apoptosis. J Hepatol 2009;50:766-778. http://dx.doi.org/10.1016/j.jhep.2008.11.025.

[94] Freischmidt A, Müller K, Ludolph AC, Weishaupt JH. Systemic dysregulation of TDP-43 binding microRNAs in amyotrophic lateral sclerosis. Acta Neuropathol Commun 2013; 1:42. http://dx.doi.org/10.1186/2051-5960-1-42.

[95] Ji J, Zhang J, Huang G, Qian J, Wang X, Mei S. Over-expressed microRNA-27a and 27b influence fat accumulation and cell proliferation during rat hepatic stellate cell activation. FEBS Lett 2009;583:759-766. http://dx.doi.org/10.1016/j.febslet.2009.01.034.

[96] Honda N, Jinnin M, Kira-Etoh T, Makino K, Kajihara I, Makino T, et al. miR-150 downregulation contributes to the constitutive type I collagen overexpression in scleroderma dermal fibroblasts via the induction of integrin $\beta 3$. Am J Pathol 2013;182:206-216. http://dx.doi.org/10.1016/j.ajpath.2012.09.023.

[97] Makino K, Jinnin M, Aoi J, Hirano A, Kajihara I, Makino T, et al. Discoidin domain receptor 2-microRNA 196a-mediated negative feedback against excess type I collagen expression is impaired in scleroderma dermal fibroblasts. J Invest Dermatol 2013;133:110-119. http://dx.doi.org/10.1038/jid.2012.252.

[98] Honda N, Jinnin M, Kajihara I, Makino T, Makino K, Masuguchi S, et al. TGF- $\beta$-mediated downregulation of microRNA-196a contributes to the constitutive upregulated type collagen expression in scleroderma dermal fibroblasts. J Immunol 2012;188: 3323-3331. http://dx.doi.org/10.4049/jimmunol.1100876.

[99] Makino K, Jinnin M, Kajihara I, Honda N, Sakai K, Masuguchi S, et al. Circulating miR-142-3p levels in patients with systemic sclerosis. Clin Exp Dermatol 2012; 37:34-39. http://dx.doi.org/10.1111/j.1365-2230.2011.04158.x.

[100] Sing T, Jinnin M, Yamane K, Honda N, Makino K, Kajihara I, et al. microRNA-92a expression in the sera and dermal fibroblasts increases in patients with scleroderma. Rheumatology (Oxford) 2012;51:1550-1556. http://dx.doi.org/10.1093/rheumatology/kes120.
[101] Zhu H, Li Y, Qu S, Luo H, Zhou Y, Wang Y, et al. MicroRNA expression abnormalities in lim- 905 ited cutaneous scleroderma and diffuse cutaneous scleroderma. J Clin Immunol 2012;32: 906 514-522. http://dx.doi.org/10.1007/s10875-011-9647-y.

[102] Shan H, Zhang Y, Lu Y, Zhang Y, Pan Z, Cai B, et al. Downregulation of miR-133 and 908 miR-590 contributes to nicotine-induced atrial remodelling in canines. Cardiovasc 909 Res 2009;83:465-472. http://dx.doi.org/10.1093/cvr/cvp130.

[103] Wang B, Koh P, Winbanks C, Coughlan MT, McClelland A, Watson A, et al. miR-200a pre- 911 vents renal fibrogenesis through repression of TGF- $\beta 2$ expression. Diabetes 2011;60: 912 280-287. http://dx.doi.org/10.2337/db10-0892.

104] Liu G, Friggeri A, Yang Y, Milosevic J, Ding Q Thannickal VJ, et al. miR-21 mediates 914 fibrogenic activation of pulmonary fibroblasts and lung fibrosis. J Exp Med 2010;207: 915 1589-1597. http://dx.doi.org/10.1084/jem.20100035.

[105] Zhong X, Chung ACK, Chen H-Y, Meng X-M, Lan HY. Smad3-mediated upregulation of 917 miR-21 promotes renal fibrosis. J Am Soc Nephrol 2011;22:1668-1681. http://dx.doi. 918 org/10.1681/ASN.2010111168.

[106] Ciechomska M, O'Reilly S, Suwara M, Bogunia-Kubik K, van Laar JM. MiR-29a reduces 920 TIMP-1 production by dermal fibroblasts via targeting TGF- $\beta$ activated kinase 1 binding 921 protein 1, implications for systemic sclerosis. PLoS One 2014;9, e115596. http://dx.doi. 922 org/10.1371/journal.pone.0115596.

[107] Jafarinejad-Farsangi S, Farazman d A, Mahmoudi M, Gharibdoost F, Karimizadeh E, 924 Noorbakhsh F, et al. MicroRNA-29a induces apoptosis via increasing the Bax:Bcl-2 ratio 925 in dermal fibroblasts of patients with systemic sclerosis. Autoimmunity 2015;48: 926 369-378. http://dx.doi.org/10.3109/08916934.2015.1030616.

[108] O'Reilly S, Ciechomska M, Fullard N, Przyborski S, van Laar JM. IL-13 mediates collagen de- 928 position via STAT6 and microRNA-135b: a role for epigenetics. Sci Rep 2016;6:25066. 929 http://dx.doi.org/10.1038/srep25066.

[109] Iwamoto N, Vettori S, Maurer B, Brock M, Pachera E, Jüngel A, et al. Downregulation of 931 miR-193b in systemic sclerosis regulates the proliferative vasculopathy by urokinase- 932 type plasminogen activator expression. Ann Rheum Dis 2016;75:303-310. http://dx. 933 doi.org/10.1136/annrheumdis-2014-205326.

[110] Polman CH, Reingold SC, Edan G, Filippi M, Hartung H-P, Kappos L, et al. Diagnostic 935 criteria for multiple sclerosis: 2005 revisions to the "McDonald Criteria.". Ann Neurol 936 2005;58:840-846. http://dx.doi.org/10.1002/ana.20703.

[111] Fenoglio C, Cantoni C, De Riz M, Ridolfi E, Cortini F, Serpente M, et al. Expression and ge- 938 netic analysis of miRNAs involved in CD4 + cell activation in patients with multiple scle- 939 rosis. Neurosci Lett 2011;504:9-12. http://dx.doi.org/10.1016/j.neulet.2011.08.021. 940

[112] Devier DJ, Lovera JF, Lukiw WJ. Increase in NF-kB-sensitive miRNA-146a and miRNA-155 941 in multiple sclerosis (MS) and pro-inflammatory neurodegeneration. Front Mol Neurosci 942 2015;8:5. http://dx.doi.org/10.3389/fnmol.2015.00005.

[113] Du C, Liu C, Kang J, Zhao G, Ye Z, Huang S, et al. MicroRNA miR-326 regulates TH-17 dif- 944 ferentiation and is associated with the pathogenesis of multiple sclerosis. Nat Immunol 945 2009;10:1252-1259. http://dx.doi.org/10.1038/ni.1798.

[114] Ahmadian-Elmi M, Bìdmeshki Pour A, Naghavian R, Ghaedi K, Tanhaei S, Izadi T, et al. 947 miR-27a and miR-214 exert opposite regulatory roles in Th17 differentiation via mediat- 948 ing different signaling pathways in peripheral blood CD4 $(+)$ T lymphocytes of patients 949 with relapsing-remitting multiple sclerosis. Immunogenetics 2016;68:43-54. http://dx. 950 doi.org/10.1007/s00251-015-0881-y.

[115] Guan H, Singh UP, Rao R, Mrelashvili D, Sen S, Hao H, et al. Inverse correlation of expres- 952 sion of microRNA-140-5p with progression of multiple sclerosis and differentiation of en- 953 cephalitogenic T helper type 1 cells. Immunology 2016;147:488-498. http://dx.doi.org/ 954 10.1111/imm.12583.

[116] Mancuso R, Hernis A, Agostini S, Rovaris M, Caputo D, Clerici M. MicroRNA-572 expres- 956 sion in multiple sclerosis patients with different patterns of clinical progression. J Transl 957 Med 2015;13:148. http://dx.doi.org/10.1186/s12967-015-0504-2. 958

[117] Bergman P, Piket E, Khademi M, James T, Brundin L, Olsson T, et al. Circulating miR-150 in 959 CSF is a novel candidate biomarker for multiple sclerosis. Neurol Neuroimmunol 960 Neuroinflammation 2016;3, e219. http://dx.doi.org/10.1212/NXI.0000000000000219. 961

[118] Christophers E. Psoriasis-epidemiology and clinical spectrum. Clin Exp Dermatol 2001; 962 26:314-320.

[119] Løvendorf MB, Mitsui H, Zibert JR, Røpke MA, Hafner M, Dyring-Andersen B, et al Laser 964 capture microdissection followed by next-generation sequencing identifies disease- 965 related microRNAs in psoriatic skin that reflect systemic microRNA changes in psoriasis. 966 Exp Dermatol 2015;24:187-193. http://dx.doi.org/10.1111/exd.12604.

[120] Ele-Refaei AM, El-Esawy FM. Effect of narrow-band ultraviolet B phototherapy and meth- 968 otrexate on microRNA (146a) levels in blood of psoriatic patients. Dermatol Res Pract 969 2015;2015:145769. http://dx.doi.org/10.1155/2015/145769.

[121] Tsuru Y, Jinnin M, Ichihara A, Fujisawa A, Moriya C, Sakai K, et al. miR-424 levels in hair 971 shaft are increased in psoriatic patients. J Dermatol 2014;41:382-385. http://dx.doi.org/ 972 10.1111/1346-8138.12460.

[122] Cheung L, Fisher RM, Kuzmina N, Li D, Li X, Werngren O, et al. Psoriasis skin 974 inflammation-induced microRNA-26b targets NCEH1 in underlying subcutaneous adi- 975 pose tissue. J Invest Dermatol 2016;136:640-648. http://dx.doi.org/10.1016/j.jid.2015. 976 12.008.

[123] Zhang W, Yi X, Guo S, Shi Q, Wei C, Li X, et al. A single-nucleotide polymorphism of miR- 978 146a and psoriasis: an association and functional study. J Cell Mol Med 2014;18: 979 2225-2234. http://dx.doi.org/10.1111/jcmm.12359. 